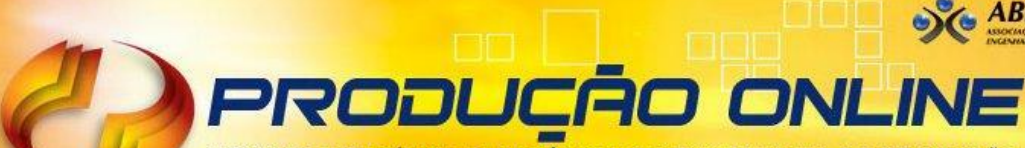 \\ REVISTA CIENTIFICA ELETRÔNICA DE ENGENHARIA DE PRODUÇÃO
}

ISSN 1676-1901

\section{DESENVOLVIMENTO DE UM MODELO DE SIMULAÇÃO NO ARENA® VISANDO O AUMENTO DA PRODUTIVIDADE EM UMA USINA DE BENEFICIAMENTO DE MINÉRIO DE FERRO}

\section{DEVELOPMENT OF A SIMULATION MODEL IN ARENA® TO INCREASE PRODUCTIVITY IN AN IRON ORE BENEFITING PLANT}

\author{
Luciano Nonato Torres* E-mail: fusktorres@hotmail.com \\ Rodrigo dos Santos Reis* E-mail: rodrigod.sr@hotmail.com \\ Samantha Rodrigues de Araújo** E-mail: samantha.r.a@hotmail.com \\ Túllio César Fernandes* E-mail: tc.f05@hotmail.com \\ ${ }^{*}$ Faculdade ALIS de Itabirito, Itabirito, MG \\ **Universidade Federal de Ouro Preto (UFOP), Ouro Preto, MG
}

\begin{abstract}
Resumo: O setor de mineração é um grande fornecedor de produtos que são utilizados pelo homem em seu cotidiano e comercializados em todo o mundo. Esta atividade necessita de alto capital financeiro e recursos tais como equipamentos pesados para transportes de matéria prima e grandes usinas de beneficiamento. Devido à grande competitividade e visibilidade principalmente no mercado externo, as empresas buscam modernizar suas operações e produzir de forma sustentável. Assim constantes mudanças nos processos se fazem necessárias, objetivando o atendimento ao cliente de forma eficaz e com a qualidade desejada. Dessa forma, o uso da tecnologia se faz cada vez mais presente nos processos e se torna uma aliada fundamental para um maior aproveitamento dos recursos e medição dos parâmetros presentes no processo produtivo, auxiliando nas tomadas de decisões. Diante disso, para esta pesquisa, a simulação de processos se apresenta como uma ferramenta poderosa que permite fazer uma comparação com a atual realidade do processo, possibilitando a realização de mudanças e acompanhamento dos resultados. Assim, este trabalho apresenta a aplicação da simulação em um processo de beneficiamento de minério de ferro a umidade natural, com o objetivo de proporcionar o aumento da produção. Como principais resultados, foram experimentados cinco cenários, sendo o quinto cenário a melhor alternativa para o aumento de produtividade na usina, proporcionando um aumento de produção de $58,42 \%$.
\end{abstract}

Palavras Chaves: Simulação. Mineração. Beneficiamento de Minério. Desenvolvimento de Cenários. Produtividade.

\begin{abstract}
The mining sector is a major supplier of products that are used by men in their daily lives and marketed around the world. This activity requires high financial capital and resources such as heavy equipment for transporting raw materials and large processing plants. Due to the great competitiveness and visibility mainly in the foreign market, companies seek to modernize their operations and produce in a sustainable way. Thus, constant changes in the processes are necessary, aiming at the customer service in an effective way and with the desired quality. Thus, the use of technology is increasingly present in the processes and becomes a fundamental ally for greater use of resources and measurement of the parameters present in the production process, assisting in decision making. Therefore, for this research, the process simulation presents itself as a powerful tool that allows to make a comparison with the current reality of the process, enabling changes to be made and the results to be monitored. Thus, this work presents the application of simulation in an iron ore beneficiation process with natural moisture, to increase production. As main results, five scenarios were tried, with the fifth scenario being the best alternative to increase productivity at the plant, providing an increase in production of $58.42 \%$.
\end{abstract}


Keywords: Simulation. Mining. Ore Beneficiation. Scenario Development. Productivity.

\section{INTRODUÇÃO}

Conforme Maria, Fernandes e Alamino (2014) o Brasil é um país que possui quantidades significativas de recursos minerais, sendo a atividade de extração responsável por $4 \%$ do PIB do país. Conforme os autores, o minério de ferro é o grande propulsor, atingindo $60 \%$ da produção mineral do Brasil. Segundo dados do Instituto Brasileiro de Mineração (IBRAM) (2019) a atividade mineradora emprega cerca de 200 mil funcionários, obtendo uma capacidade de exportação de 409 milhões de toneladas, representando o montante de 29,9 bilhões de dólares somente no ano de 2018. Assim, é notável o desenvolvimento econômico que a mineração provoca nas localidades em que estão situadas. (ÉNRIQUEZ; FERNANDES; ALAMINO, 2011).

Apesar das vantagens econômicas proporcionadas pela atividade de extração, vale destacar que existem alguns desafios a serem enfrentados, tais como o custo elevado de investimento e a dificuldade expressiva para alteração de sistemas e maquinários já implantados (RACIA, 2016). Com o objetivo de reduzir às incertezas e obter a maximização do lucro, as mineradoras têm utilizado a Pesquisa Operacional (PO) em busca de técnicas de simulação como ferramenta estratégica para melhorar seus resultados, conforme demonstrado nas pesquisas de Araújo et al. (2020), Rodrigues (2006), Souza (2009) e Gonçalves (2019).

Com o acidente ocorrido em Brumadinho no estado de Minas Gerais, as empresas têm buscado a eliminação da produção de minério de ferro com a geração de rejeito em forma de polpa. Para tanto, as mineradoras precisam realizar mudanças no processo do beneficiamento de minério de ferro, utilizando-se de técnicas de tratamento por umidade natural, eliminando a utilização de barragens, tornando assim, o ambiente operacional mais seguro.

Diante disso, o objetivo da presente pesquisa, é estudar uma usina beneficiadora de minério de ferro através da técnica de simulação a fim de verificar a possibilidade de aumento na produção, identificando os gargalos do processo bem como sua capacidade de produção. Para que o objetivo geral fosse alcançado, se fez necessário: (1) identificar a capacidade de cada equipamento da estação de 
tratamento de minério; (2) desenvolver um modelo de simulação; (3) submeter o modelo a diversos cenários; (4) propor estratégia de produção mais eficaz a partir do estudo realizado com objetivo de aumentar a produção.

\section{DESENVOLVIMENTO}

\subsection{Mineração}

Segundo dados do ministério de Minas e Energia (MME,2019), o setor mineral é constituído das áreas de geologia, mineração e transformação mineral, o qual forma uma base para variadas cadeias produtivas que possui como objetivo atender $\mathrm{o}$ consumo da sociedade moderna e consequentemente garantir 0 desenvolvimento mundial.

O setor mineral é responsável por $4,2 \%$ do Produto Interno Bruto (PIB) do país e 20\% das importações brasileiras (IBRAM, 2018). O instituto ainda afirma que, além de ser considerada como indústria base, a mineração também impulsiona a economia com geração de empregos e renda, pagamento de tributos e compensações financeiras (repasses financeiros aos municípios pela exploração mineral). Vale destacar que os investimentos destinados ao setor mineral totalizarão US\$270 bilhões até 2030 (MME, 2019).

Para Schneider et al. (2016) o foco do processamento mineral é o aproveitamento máximo dos recursos do subsolo, visando a sustentabilidade e o esforço para redução dos custos operacionais, bem como a priorização de equipamentos e processos cada vez mais eficientes.

Segundo Ceciliano (2007) e Luz, Sampaio e França (2010) o cenário mundial da mineração vem se transformando devido aos avanços tecnológicos e as preocupações com a utilização dos recursos ambientais, como a água por exemplo. Tais mudanças obrigam as organizações a adotarem tecnologias que as façam minimizar os impactos com as interfaces dos processos, reduzindo os custos e aumentando a produtividade.

Os avanços tecnológicos e computacionais permitiram a automatização dos processos da mineração (ALEXANDRE; BECK e GIORGIO, 2012), dessa forma, as empresas buscam melhorar seus processos e controles com a utilização de 
sistemas e ferramentas que facilitem o entendimento e desenvolvimento da organização. Um exemplo importante de tais ferramentas é o Enterprise Resource Planning (ERP) que possui a finalidade de integrar a maioria dos dados dos processos da empresa, armazenando, disseminando e possibilitando o fluxo das informações (ALEXANDRE; BECK; GIORGIO, 2012; TURBAN; MCLEAN; WETHERBE, 2004).

Assim novas iniciativas de melhoria nos processos vêm sendo utilizadas, devido ao aprofundamento dos conceitos de programação matemática, avanços das técnicas de PO, bem como a utilização de técnicas de simulação (CECILIANO, 2007). O mesmo autor afirma que os processos de mineração que possuem variáveis que assumem comportamento estocástico, têm adotado técnicas de simulação a fim de encontrar os gargalos, auxiliar no dimensionamento dos recursos (equipamentos, mão de obra, energia...), e na análise de custo relacionado aos diferentes cenários, proporcionando apoio nas tomadas de decisões, garantindo assim a perpetuidade do negócio.

\subsubsection{Processo produtivo do minério de ferro}

Para Luz, Sampaio e França (2010), o processo de tratamento ou beneficiamento de minérios consiste em um conjunto de operações que visam modificar a granulometria, concentrar as espécies de minerais sem que necessariamente mude os aspectos físicos ou químicos desses materiais.

A atividade de minerar baseia-se em três principais atividades: (1) descobrir os recursos minerais no subsolo, (2) trazer esses recursos presentes no subsolo para a superfície e enfim (3) submetê-los a processos industriais a fim de qualificálos para o uso industrial (CHAVES, 2002). No que se refere à terceira etapa, comumente denominada beneficiamento dos minerais, vale destacar que esta possui a funcionalidade de reduzir e separar os minerais (por tamanhos e espécies), através da combinação de um conjunto de operações sequenciadas com o objetivo de se obter os produtos exigidos pelo mercado.

Ainda segundo Chaves (2002) o processamento do minério de ferro consiste em uma sequência de operações unitárias com o intuito de atingir um objetivo específico ou potencializar uma característica do mineral. Ainda conforme o autor, 
apenas uma operação unitária não é responsável por produzir um produto. Dessa forma, o processo necessita de várias combinações de operações unitárias desde a alimentação da usina com o minério lavrado na mina (run-of-mine (ROM)), até a obtenção do produto.

Conforme Chaves (2002), as operações unitárias do processo de beneficiamento são:

- Operações de cominuição: são etapas sucessivas de britagem e moagem que visam adequar os tamanhos das partículas aos diferentes processos e/ou mercado a que se destinam; são apoiadas por operações de separação das partículas, em geral por peneiras e classificadores.

- Operações de concentração: buscam a separação seletiva das partículas minerais não só por espécies minerais, mas também por diferentes graus de pureza.

- Operações auxiliares: que transportam e/ou armazenam os variados produtos entre as diferentes operações unitárias, além de auxiliarem na retirada de água contida nos produtos, são elas: (1) transporte de sólidos particulados, (2) transporte de sólidos em suspensão em água (em polpa), (3) estocagem, (4) homogeneização em pilhas, (5) estocagem em silos, (6) espessamento, (7) filtragem e (8) secagem.

A Figura 1 apresenta um fluxograma de tratamento de minérios, mostrando as respectivas operações unitárias.

Para Luz, Sampaio e França (2010) e Chaves (2003) a operação de cominuição consiste em reduzir o tamanho de um sólido em fragmentos de tamanhos menores, através da ação de força mecânica. Este processo inclui diversos estágios, desde a lavra, sendo o primeiro estágio de fragmentação, com a utilização de explosivos, em que blocos volumosos são adequados aos equipamentos posteriores de britagem (conjunto de operações que objetiva diminuir o tamanho dos blocos oriundos da lavra, levando-os para granulometrias desejadas para utilização direta ou posterior processamento). 
Figura 1 - Etapas do tratamento do minério

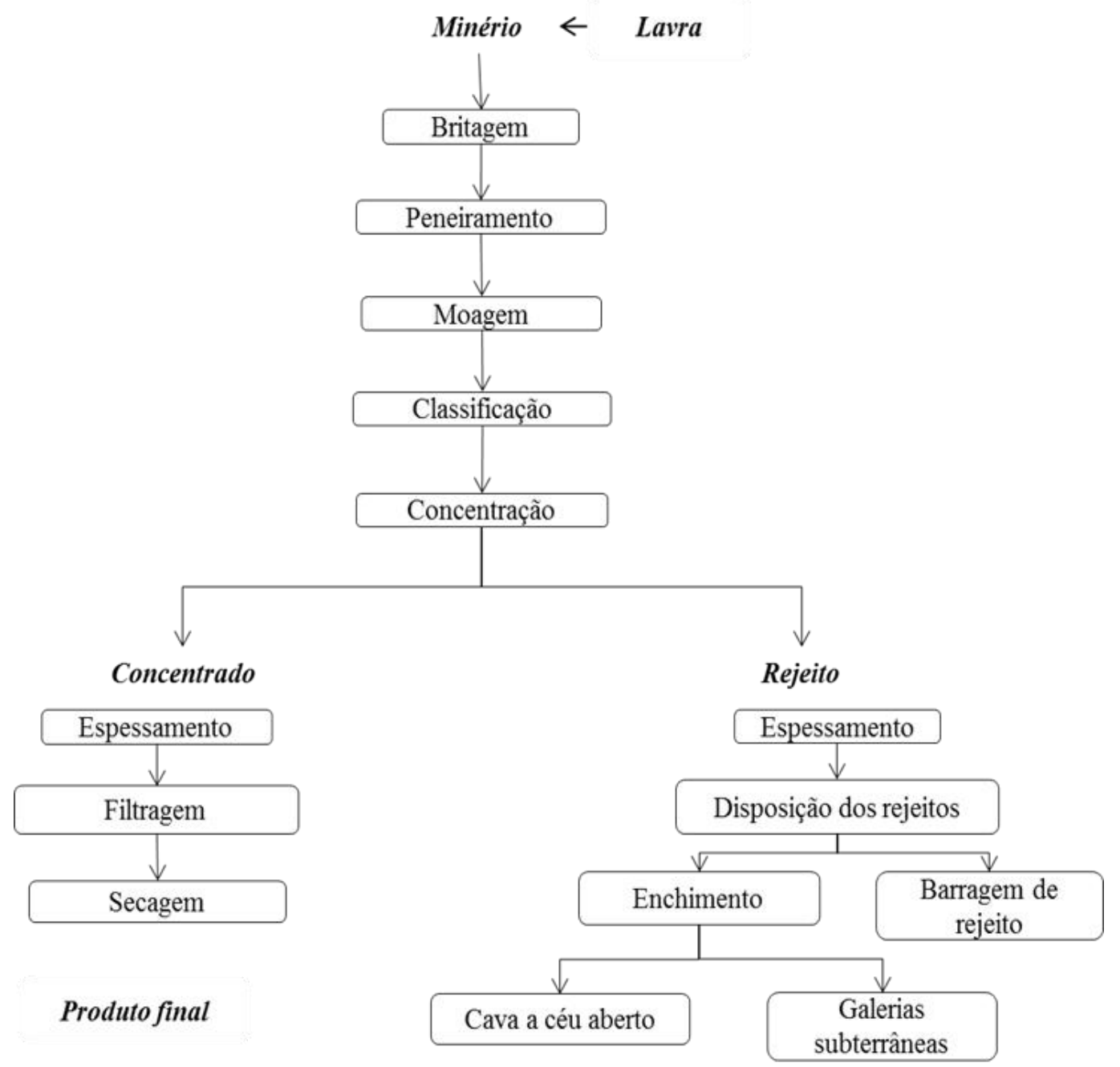

Fonte: Luz Sampaio e França (2010).

Ainda para Chaves (2003) as operações de cominuição são necessárias para permitir o manuseio do minério, bem como o transporte contínuo em transportadores de correias e caminhões e a utilização do minério dentro dos processos industriais, que necessitam de características granulométricas específicas.

A fragmentação acontece em três estágios, (1) grossa e (2) intermediária com a utilização de britadores e granulometria (3) fina realizada por moinhos, (LUZ, SAMPAIO e FRANÇA, 2010). O Quadro 1 apresenta a classificação dos estágios de britagem. 
Quadro 1 - Classificação dos estágios de britagem

\begin{tabular}{|l|c|c|}
\hline Estágio de Britagem & $\begin{array}{c}\text { Tamanho Máximo de } \\
\text { Alimentação }(\mathbf{m m})\end{array}$ & $\begin{array}{c}\text { Tamanho Máximo de } \\
\text { Produção }(\mathbf{m m})\end{array}$ \\
\hline Britagem Primária & 1000 & 100 \\
\hline Britagem Secundária & 100 & 10 \\
\hline Britagem Terciária & 10 & 1 \\
\hline Britagem Quaternária & 5 & 0,8 \\
\hline
\end{tabular}

Fonte: Luz, Sampaio e França (2010).

Segundo Chaves (2003) a etapa de peneiramento consiste na separação de um material em duas ou mais frações com tamanhos granulométricos distintos, por meio de um gabarito de abertura fixa e pré-determinada. Os gabaritos podem ser grelhas de barras paralelas, telas de malhas quadradas, retangulares e alongadas, telas de fios paralelos, chapas perfuradas e placas fundidas.

A separação leva em consideração o tamanho geométrico das partículas (LUZ, SAMPAIO e FRANÇA 2010) e cada partícula tem a possibilidade de passar pela abertura ou ficar retida. As partículas retidas são denominadas oversize e o mineral passante undersize (CHAVES, 2003).

Estes mesmos autores dizem que, os peneiramentos industriais acontecem de forma úmida (quando se adiciona água no processo) método este utilizado nas operações de classificação (que não é de interesse dessa pesquisa) e a seco quando é realizado com o material na sua umidade natural.

Conforme pesquisa de Ceciliano (2007) as operações de beneficiamento de minério se tornam economicamente viáveis se forem realizadas em grande escala de produção (milhões de toneladas/ano) isso, devido ao baixo valor unitário da tonelada. Assim é necessário que todas as etapas do processo sejam bem dimensionadas e controladas, minimizando os custos e garantindo a qualidade dos produtos.

\subsection{Modelos de simulação e Simulação Computacional}

Segundo Pidd (1998) a modelagem consiste no ponto de partida para o desenvolvimento de um estudo de simulação. Dessa forma, o objetivo do desenvolvimento de um modelo é buscar a compreensão do processo em estudo, podendo assim, obter uma visão clara da operação diária de um sistema, além de 
identificar o grau de complexidade que será considerado no modelo (KELTON, RANDALL, STURROCK, 2004; RODRIGUES, 1994).

Vale destacar que o modelo de simulação não é apenas a representação do processo real, mas sim uma transcrição deste processo com um objetivo bem definido, a fim de permitir a equipe analisar, entender, alterar e gerenciar a realidade (PIDD, 1998; LAW, 2007). Mediante os estudos de Ceciliano (2007) é possível observar que o processo de modelagem (Figura 2) além de utilizar diversas áreas do conhecimento, como a estatística e a PO, exige ainda do desenvolvedor grande capacidade criativa que, unida com ferramentas adequadas, tais como fluxogramas, softwares de simulação, entre outros, podem erigir resultados significativos durante os estudos.

Figura 2 - Etapas da modelagem

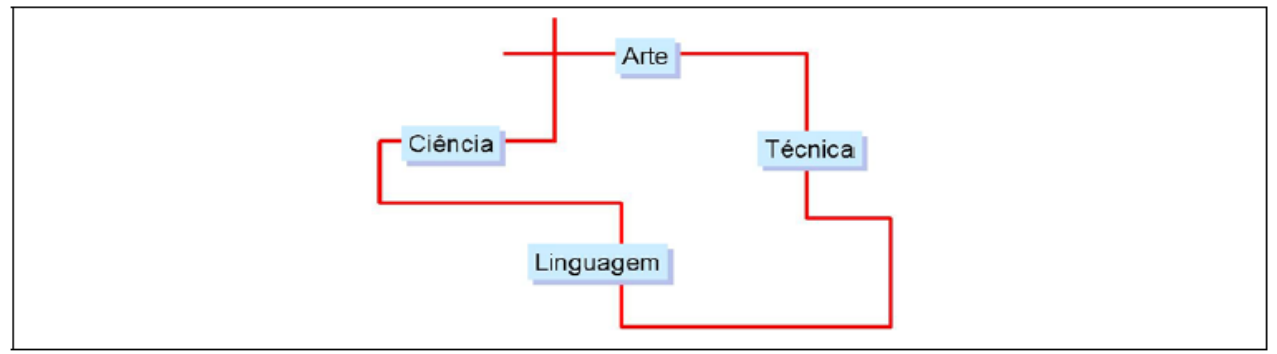

Fonte: Ceciliano (2007).

Banks et al. (2010), destacam a importância do desenvolvimento de um modelo de simulação, já que este permite ao tomador de decisão visualizar as conexões e interações entre os equipamentos, conseguindo assim definir sua capacidade. Além disso, o autor destaca que é possível prever como o sistema irá se comportar em diferentes cenários.

Para Kelton, Randall e Sturrock, (2004) e Szymankiewicz, Mcdonald e Turner (1988), a simulação computacional consiste no estudo de cenários transcritos em modelos matemáticos. Conforme autores, a simplificação da realidade captadas por meio da modelagem, se torna possível mediante a utilização de softwares de simulação como, por exemplo, o ARENA ${ }^{\circledR}, \mathrm{R}$ e o Lindo. Os autores destacam a relevância de um modelo de simulação, afirmando que este permite interpretar o sistema de forma clara, a partir de condições pré-estabelecidas e experimentos numéricos realizados ao longo do tempo. 
A simulação consiste na representação dos processos de operação do mundo real ao longo do tempo através de um modelo computacional (Banks et al., 2005; Pedgen et al.,1999). Conforme os autores, a simulação permite o estudo das interações entre os agentes do sistema, com objetivo de auxiliar na compreensão do comportamento do processo real e reduzir as incertezas, sendo, portanto, uma ferramenta poderosa nas decisões estratégicas.

Law (2007) e Bodon (2011) ressaltam que a simulação consiste na reprodução das atividades ou processos do mundo real em um ambiente virtual, permitindo a análise de sistemas estocásticos complexos, em menor tempo e com menor custo, proporcionando aos gestores uma alternativa racional e quantitativa a fim de prever erros que acarretam em gastos elevados.

Panagiotou (1999) e Vagenas (1999) afirmam que a simulação computacional é um recurso relevante devido ao baixo custo dos computadores e aos importantes resultados proporcionados, como por exemplo, redução de filas e a taxa de utilização dos equipamentos. Além disso, os autores destacam a velocidade em que os modelos são desenvolvidos, bem como a forma vertiginosa com que este possibilita atualizações. Entretanto, no que se refere a velocidade de desenvolvimento dos modelos, não há consenso na literatura, conforme observado por Pidd (1998) e Negahban e Smith (2014), os quais afirmam que o desenvolvimento de um modelo de simulação, em alguns casos, pode ser ímprobo e necessitar de ferramentas computacionais de alto valor, mediante a complexidade do problema a ser solucionado.

A utilização de animação durante as simulações vem proporcionando notoriedade e credibilidade para os modelos desenvolvidos, despertando a atenção da liderança, facilitando a visualização das melhorias realizadas a partir de modelos de simulação (LAW; KELTON, 1991).

\subsubsection{Modelos referentes a um estudo simulação}

Existem diversas metodologias utilizadas para realizar um estudo de simulação como, por exemplo, as propostas por Banks et al. (2010), Law (2007) e Freitas Filho (2008), sendo estas apresentadas conforme Figura 4. 
Figura 3 - Metodologias referente a um estudo de simulação
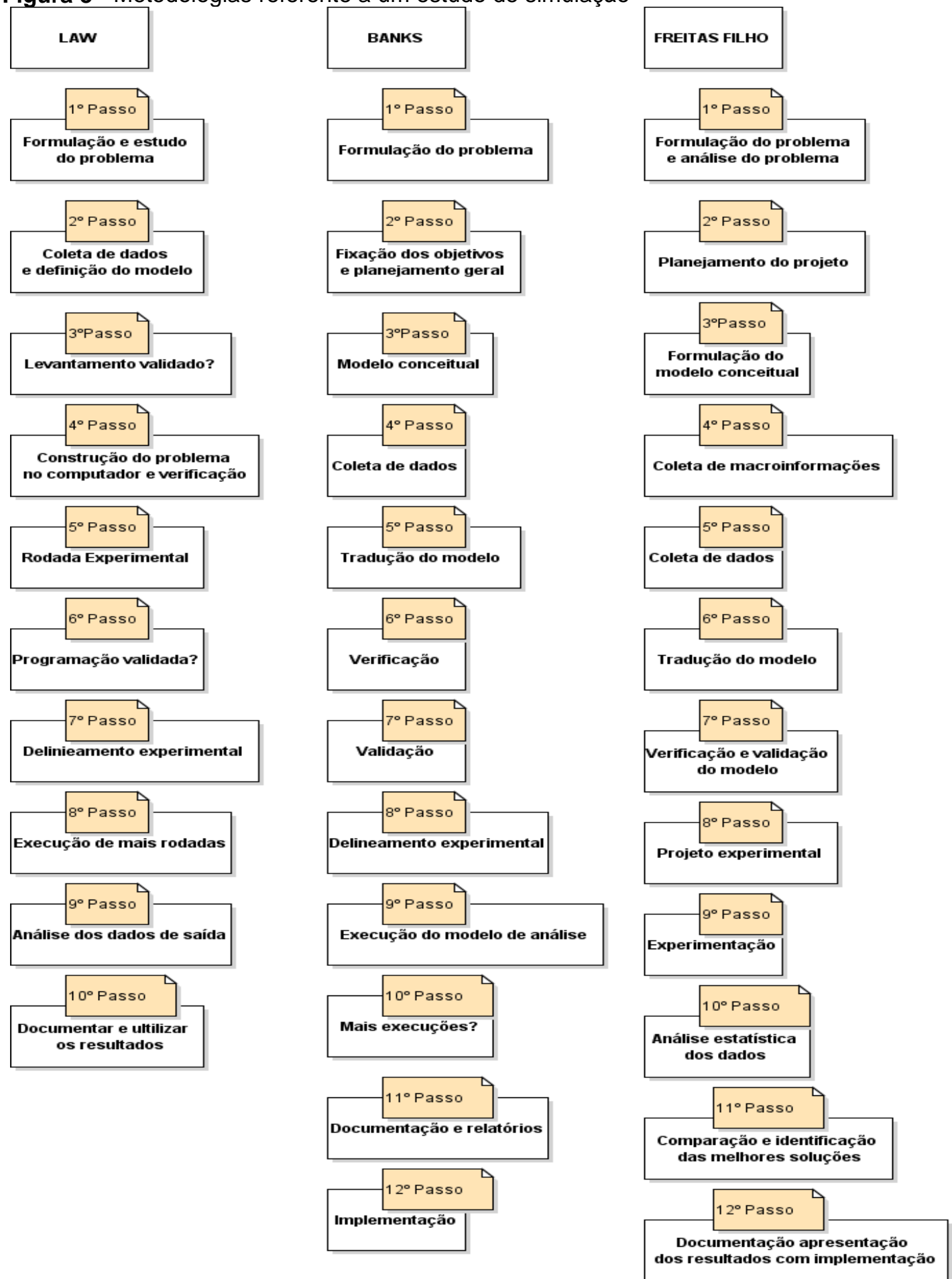

Fonte: Adaptado de Nascimento e Rangel (2014).

Tais metodologias, consistem em um conjunto de fases ou etapas, as quais possuem entradas e saídas bem definidas, que estruturam e organizam o desenvolvimento de um estudo de simulação. Vale destacar que a definição do problema do sistema real, impacta de forma significativa o estudo de simulação.

Revista Produção Online. Florianópolis, SC, v. 21, n. 2, p. 576-607, 2021 
Assim, as organizações que não planejam ou não estruturam as atividades de simulação, podem apresentar desvantagens, dentre as quais se destacam: o aumento do custo dos projetos bem como a geração de resultados incorretos que induzem a decisões equivocadas.

\subsubsection{Onde utilizar simulação}

A simulação pode ser utilizada nas várias áreas das organizações (operacional, vendas, engenharia, etc.) a fim de auxiliar na tomada de decisão, visando avaliar os possíveis cenários em um determinado intervalo de tempo.

Segundo Araújo et al. (2020) e Carneiro (2014) uma aplicação importante do estudo de simulação consiste em analisar os processos de tráfegos dos caminhões carregados e vazios entre as origens e destinos dentro de uma mineração.

Já conforme Corrêa, Mello e Pereira (2014) outra aplicação importante da simulação é em uma linha de montagem automotiva com o intuito de identificar o impacto do fator humano na linha de produção.

Santos et al. (2014) analisaram por meio de simulação e otimização o funcionamento operacional de um restaurante self-service de pequeno porte.

\subsubsection{Vantagens e desvantagens da simulação}

Segundo Law (2007), Banks et al. (2005), Gavira (2003) e Andrade (2002) as vantagens da simulação são normalmente mais relevantes que os problemas a ela relacionados, e dentre as principais vantagens, se destacam: (1) desenvolvimento de modelos realistas, (2) processo de modelagem evolutivo, (3) aplicação em sistemas mal estruturados, (4) facilidade de comunicação, (5) soluções rápidas (após a elaboração do modelo), (6) escolha correta dos recursos num dado problema, (7) flexibilidade, (8) diagnóstico de problemas, (9) visualização de planos, (10) construção de consenso, (11) treinamento de equipe e por fim, a principal vantagem que consiste no (12) controle do tempo em qualquer horizonte de cenário.

Já as desvantagens são expostas pelos mesmos autores, dentre as quais se destacam: (1) construção do modelo somente após treinamento especializado, 
(2) dificuldade de interpretação dos resultados obtidos após a simulação, (3) dificuldade na modelagem, (4) dificuldade na implementação dos resultados.

\section{METODOLOGIA}

As pesquisas podem ser classificadas conforme os seguintes parâmetros: abordagem, natureza, objetivos e procedimentos. (SILVEIRA e GERHARDT, 2009). Sendo assim, no que se refere a abordagem, essa pesquisa é classificada como quantitativa e qualitativa.

No que se refere a natureza, este trabalho é classificado como uma pesquisa aplicada, uma vez que analisa e estuda um caso específico, o qual retrata a transformação de uma usina de beneficiamento de minério a úmido em beneficiamento por umidade natural.

Quanto aos seus objetivos, este trabalho é classificado como exploratório, uma vez que se pretende propor soluções para os gargalos bem como desenvolver hipóteses para a solução dos problemas encontrados na usina de beneficiamento.

E por fim, referente aos procedimentos, o presente estudo é classificado como estudo de caso, já que consiste no estudo profundo e detalhado do objeto em análise, visando conhecimento amplo (GIL, 2002).

\subsection{Metodologia de simulação}

Para a presente pesquisa, a metodologia adotada para o desenvolvimento do estudo de simulação, consiste em uma adaptação das metodologias propostas por Banks et al. (2010) e Law (2007) apresentadas na seção 2.2.1, já que, conforme Rangel e Nascimento (2014), estas metodologias proporcionam melhor identificação dos elementos fundamentais no desenvolvimento de um modelo de simulação. Assim, a metodologia adotada pela presente pesquisa, está apresentada conforme Figura 5 e possui as seguintes etapas: (1) formulação e estudo do problema, (2) definição dos objetivos, (3) desenvolvimento do modelo conceitual, (4) coleta de dados, (5) tradução do modelo de simulação, (6) verificação e validação do modelo, (7) desenvolvimento de cenários, (8) verificação dos dados de saída e (9) implementação do modelo. 
Figura 4 - Etapas do modelo de simulação

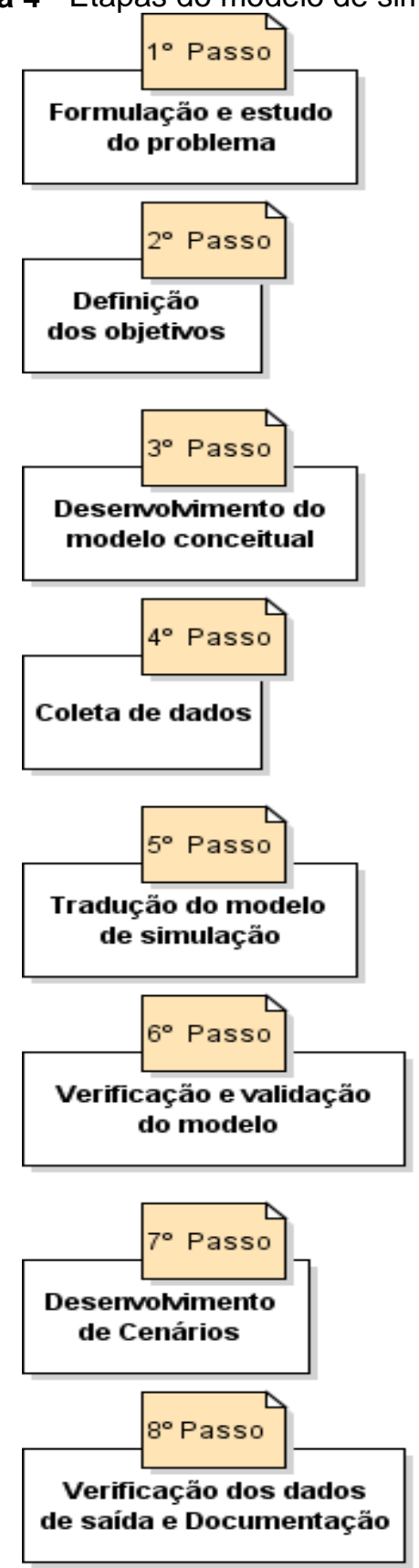

Fonte: Adaptado de Banks et al. (2010) e Law (2007)

\subsection{Formulação do problema}

A usina em que a presente pesquisa foi desenvolvida é caracterizada por um processo a umidade natural, ou seja, não há a utilização de água durante o processamento do minério, consistindo apenas nas operações de britagem e classificação. Assim, o objetivo da usina é a transformação e classificação 
granulométrica do minério através de processos (britagem e peneiramento), a fim de satisfazer as necessidades dos clientes.

No que se refere aos tipos e quantidades dos equipamentos (recursos) utilizados no processamento do minério, são estes: um alimentador vibratório (AV01), um alimentador de correia (AL02), um britador de mandíbula (BR01), duas peneiras (PE01 e PE02), oito transportadores de correia (TC01, TC02, TC03, TC04, TC05, TC05A, TC06 e TC08) e dois britadores cônicos (BR02 e BR03), dispostos em uma lógica de processo conforme mostrado na Figura 6.

Figura 5- Fluxograma da usina

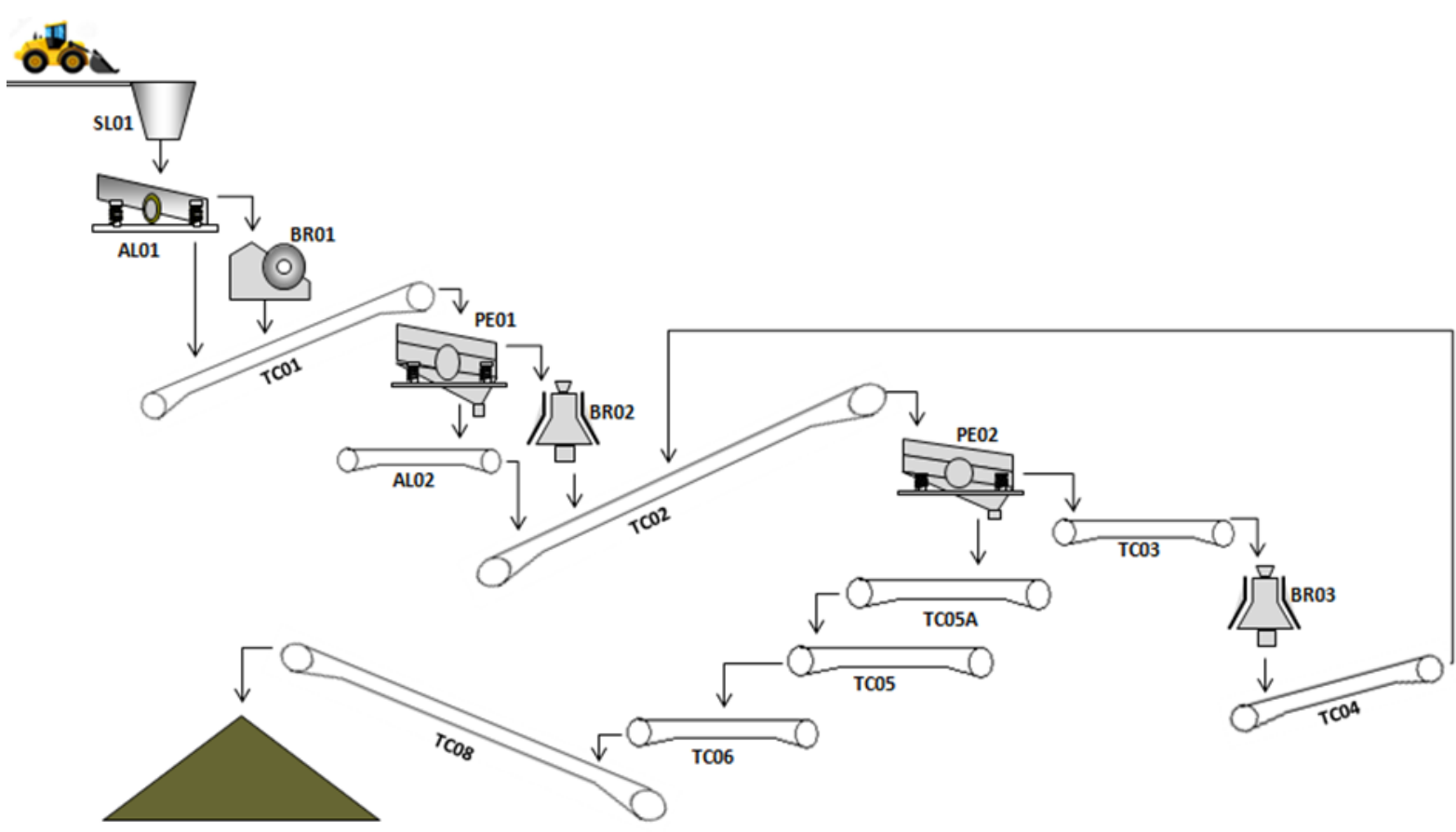

Conforme Figura 6, o ROM é inserido no processo por meio de carregadeiras em um silo (SL01), iniciando a alimentação da usina. Vale destacar que nessa etapa, o ROM possui tamanho e formas variadas, podendo alcançar tamanhos superiores a $1000 \mathrm{~mm}$. O ROM é então transportado pelo alimentador vibratório AV01, (uma mesa de vibração, dotada de uma grelha que realiza a préclassificação de partículas finas, no caso, menor que $100 \mathrm{~mm}$ ) para o processo de britagem ou para a TC01.

O processo de britagem permite a redução das partículas com objetivo de atender a especificação granulométrica do produto. Para tanto, a redução direta das partículas realizadas pelos britadores acontece em três etapas de britagem: primária, secundária e terciária.

Revista Produção Online. Florianópolis, SC, v. 21, n. 2, p. 576-607, 2021 
No presente processo, a britagem primária acontece através da utilização de britadores de mandíbulas, com abertura que variam de 90 a $100 \mathrm{~mm}$, com o intuito de possibilitar o transporte do material em uma correia transportadora. O produto do britador de mandíbula BR01, se junta à fração fina da mesa vibratória no transportador de correia TC01. Assim, o material segue para a primeira classificação, que acontece na peneira PE01.

O material retido da peneira PE01 (oversize), com fração granulométrica acima de $32 \mathrm{~mm}$, segue para a britagem secundária, alimentando o britador cônico BR02, com abertura de $28 \mathrm{~mm}$. O passante da peneira (undersize) é direcionado ao AL02 que alimenta o transportador de correia TC02, o qual recebe também o minério britado no britador BR02.

O transportador de correia TC02 transporta o minério até a peneira PE02, que realiza a segunda classificação das partículas. As partículas com tamanho menor que a abertura da tela instalada na peneira PE02 $(19 \mathrm{~mm})$ seguem para o transportador TC05A, sendo transportado e direcionado para os transportadores TC05, TC06 e TC08 sucessivamente, até a pilha de produto. Já o material retido na peneira PE02, ou seja, material cujas partículas são maiores que a abertura da tela, é transportado pelo transportador TC03 para a britagem terciária realizada no britador BR03 (britador cônico com regulagem em 19 mm). Esse material proveniente da britagem terciária, também chamado de carga circulante, é transportado pelo transportador TC04 e retorna ao transportador TC02, para ser novamente classificado na peneira PE02.

O produto final da usina é chamado de coarse sínter feed, ou seja, o minério de ferro com classificação granulométrica até $6,3 \mathrm{~mm}$. Vale destacar que esse minério é utilizado como blend para adequação de qualidade nos minérios de ferro das minas do norte do Brasil, uma vez que a qualidade do minério presente em tais minas (teor de ferro $>68 \%$ ) é superior a necessidade dos clientes. E por fim, o produto é empilhado em uma área ao final do processo, sendo retirado posteriormente por caminhões e direcionado ao seu destino final.

\subsection{Definição dos objetivos da simulação}

Os objetivos do presente estudo de simulação consistem em: 
1 - Identificar as restrições do sistema;

2 - Desenvolver propostas de cenários a fim de analisar o impacto na produção.

\subsection{Desenvolvimento do modelo conceitual}

Um modelo conceitual deve transcrever um cenário real com a finalidade de facilitar a interpretação do sistema e garantir ao desenvolvedor uma sequência de programação a ser seguida.

O modelo conceitual referente ao presente estudo, pode ser observado conforme a Figura 7, e consiste na transcrição do processo real de forma objetiva, através da definição das principais atividades que devem ser modeladas na ferramenta computacional. Vale ressaltar que nesta etapa, não há necessidade de se definir de forma detalhada as variáveis do processo, tais como: tempo de execução das atividades, capacidades dos recursos, bem como os custos envolvidos. 
Figura 6- Modelo conceitual

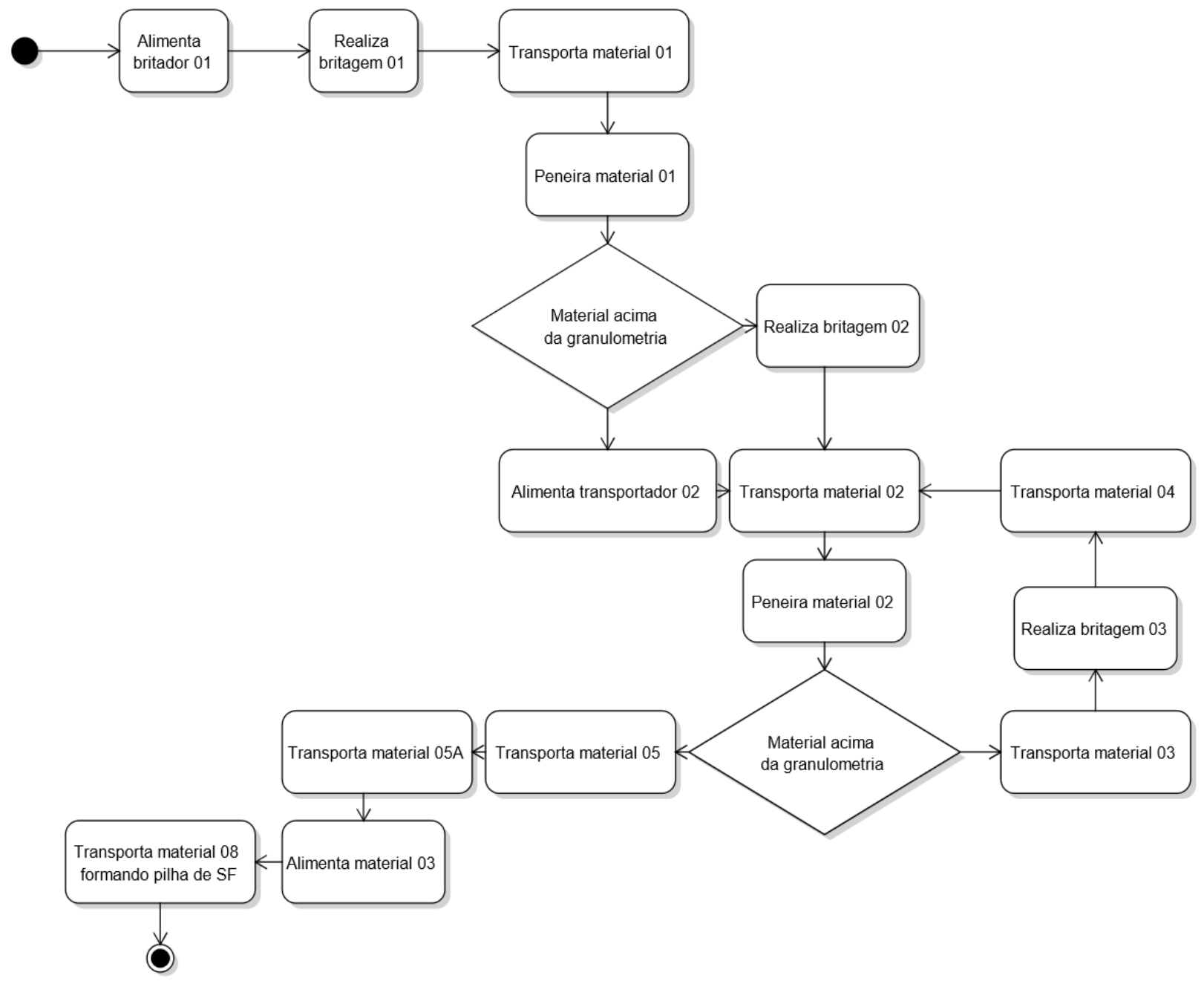

\subsection{Coleta de dados}

Os dados que foram inseridos no modelo de simulação, são provenientes de manuais dos equipamentos utilizados no processo, de testes realizados em laboratório e de um sistema de informação responsável pelo arquivamento de informações relativas ao processo.

Dentre os dados inseridos no modelo, a taxa de alimentação da usina foi coletada através de um sistema de informação responsável pelo monitoramento e controle, bem como o armazenamento das informações referentes ao processo. Dessa forma, foram coletados 1949 dados de alimentação da usina (tonelada/hora). Depois de coletados, tais dados foram inseridos na ferramenta Input Analyser do software ARENA ${ }^{\circledR}$, e transformados na função de distribuição $\operatorname{NORM}(2.95,0.408)$ minutos, que caracteriza o comportamento dos dados coletados. 
Os dados relativos aos recursos utilizados no modelo de simulação foram obtidos por meio dos manuais dos equipamentos e podem ser observados conforme Quadro 2.

Quadro 2- Dados de entrada

\begin{tabular}{|c|c|c|}
\hline Equipamentos & Descrição & Capacidade \\
\hline AL01 & Capacidade do alimentador & 400 a $600 \mathrm{ton} / \mathrm{h}$ \\
\hline PE01 & Peneira vibratória & 300 ton/h \\
\hline PE02 & Peneira vibratória & 180 ton/h \\
\hline BR01 & Britador de mandíbula & 275 ton/h \\
\hline BR02 & Britador cônico & 170 a 220 ton/h \\
\hline BR03 & Britador cônico & 150 a $190 \mathrm{ton} / \mathrm{h}$ \\
\hline TC01 & Correia transportadora & $1,760 \mathrm{~m} / \mathrm{s}$ \\
\hline TC02 & Correia transportadora & $1,830 \mathrm{~m} / \mathrm{s}$ \\
\hline TC03 & Correia transportadora & $1,860 \mathrm{~m} / \mathrm{s}$ \\
\hline TC04 & Correia transportadora & $1,980 \mathrm{~m} / \mathrm{s}$ \\
\hline TC05 & Correia transportadora & $1,780 \mathrm{~m} / \mathrm{s}$ \\
\hline TC05A & Correia transportadora & $1,820 \mathrm{~m} / \mathrm{s}$ \\
\hline TC06 & Correia transportadora & $1,670 \mathrm{~m} / \mathrm{s}$ \\
\hline TC08 & Correia transportadora & $2,650 \mathrm{~m} / \mathrm{s}$ \\
\hline & & \\
\hline & & \\
\hline
\end{tabular}

Já os dados inseridos nos pontos de decisões do modelo de simulação, foram obtidos por testes realizados em laboratório.

Os pontos de decisões do modelo são estruturas de programação que permitem que a entidade (minério) "tome uma decisão" de caminho no processo. Tais pontos de decisão estão destacados conforme Figura 8. 
Figura 7 - Pontos de decisões do modelo

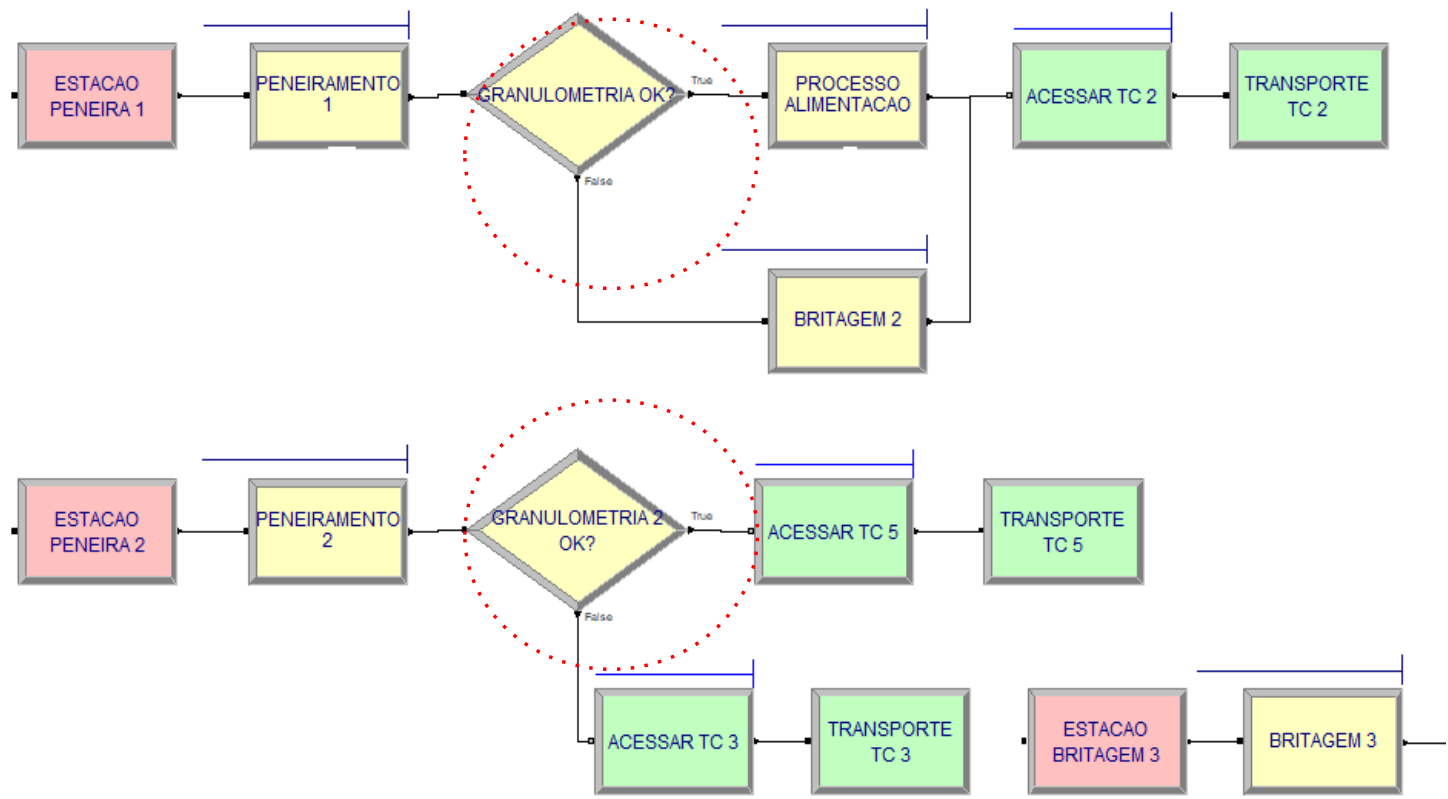

Como pode-se observar na Figura 8, os pontos de decisões do modelo, são responsáveis por definir a quantidade de material que será processado na segunda e terceira britagem, sendo que a condição para que o material seja encaminhado para tais processos é a não conformidade da granulometria do material, ou seja, são grãos de minério com a granulometria maior que $32 \mathrm{~mm}$ no caso da classificação conforme PE01 e 19 mm no caso da PE02.

Contudo, a granulometria do material que alimenta a usina varia de acordo com o tipo de material extraído, sendo que esta variação ocorre devido a frente de extração na mina.

O material que alimenta a usina estudada é proveniente de duas minas distintas: mina Sapecado e mina Galinheiro. Já os tipos de materiais extraídos das duas minas podem ser classificados como: (1) material tipo canga e (2) material tipo hematita. Vale destacar que o material tipo canga são minerais que recobrem os depósitos minerais e possuem formações oxidadas de seu mineral, podendo ser $\mathrm{Fe}, \mathrm{Al}$ ou Mn (HENRIQUES, 2012). Conforme mesmo autor, o material hematita $\left(\mathrm{Fe}_{2} \mathrm{O}_{3}\right)$ consiste em um mineral que possui teor de ferro acima de $56 \%$ e teores de sílica menores que $10 \%$, podendo ainda se apresentar na forma especial (com teores de sílicas inferiores a $4 \%$ ).

Para a definição da quantidade de material que passa pelo processo de britagem 2 e britagem 3, foram realizadas análises de amostras de material tipo 
canga e tipo hematita coletadas em ambas as minas Sapecado e Galinheiro. Foram então coletadas dez amostras, sendo cinco amostras de material tipo canga e cinco amostras de material tipo hematita. Cada amostra foi coletada com massa de aproximadamente $50 \mathrm{~kg}$ e enviadas a um laboratório de peneiramento especializado para análise.

Os resultados provenientes das amostras apresentam o percentual passante (material que não possui a necessidade de ser britado) de acordo com a granulometria do material coletado em milímetros $(\mathrm{mm})$ e, dessa forma, são apresentados na Tabela 1 os resultados referentes a média das 5 amostras de material tipo canga coletadas nas minas de Galinheiro e Sapecado.

Tabela 1- Classificação da granulometria (material tipo canga)

\begin{tabular}{cccc}
\hline \multicolumn{2}{c}{ Canga Galinheiro } & \multicolumn{2}{c}{ Canga Sapecado } \\
Tamanho (mm) & Passante (\%) & Tamanho (mm) & Passante (\%) \\
\hline 63,54 & 100 & 63,54 & 100 \\
50,8 & 98 & 50,8 & 94 \\
44,5 & 97 & 44,5 & 92 \\
37,5 & 95 & 37,5 & 87 \\
31,5 & 93 & 31,5 & 84 \\
25,4 & 85 & 25,4 & 76 \\
19,1 & 78 & 19,1 & 72 \\
15,87 & 73 & 15,87 & 67 \\
12,74 & 68 & 12,74 & 61 \\
9,52 & 62 & 9,52 & 53 \\
6,35 & 52 & 6,35 & 41 \\
4,76 & 47 & 4,76 & 35 \\
2,38 & 37 & 2,38 & 26 \\
1,19 & 29 & 1,19 & 20 \\
0,6 & 23 & 0,6 & 16 \\
0,3 & 21 & 0,3 & 12 \\
0,15 & 14 & 0,15 & 9 \\
0,07 & 6 & 0,07 & 4 \\
\hline
\end{tabular}

O Gráfico 1 apresenta a dispersão dos dados da Tabela 1 conforme os valores amostrados. 
Gráfico 1 - Material tipo canga

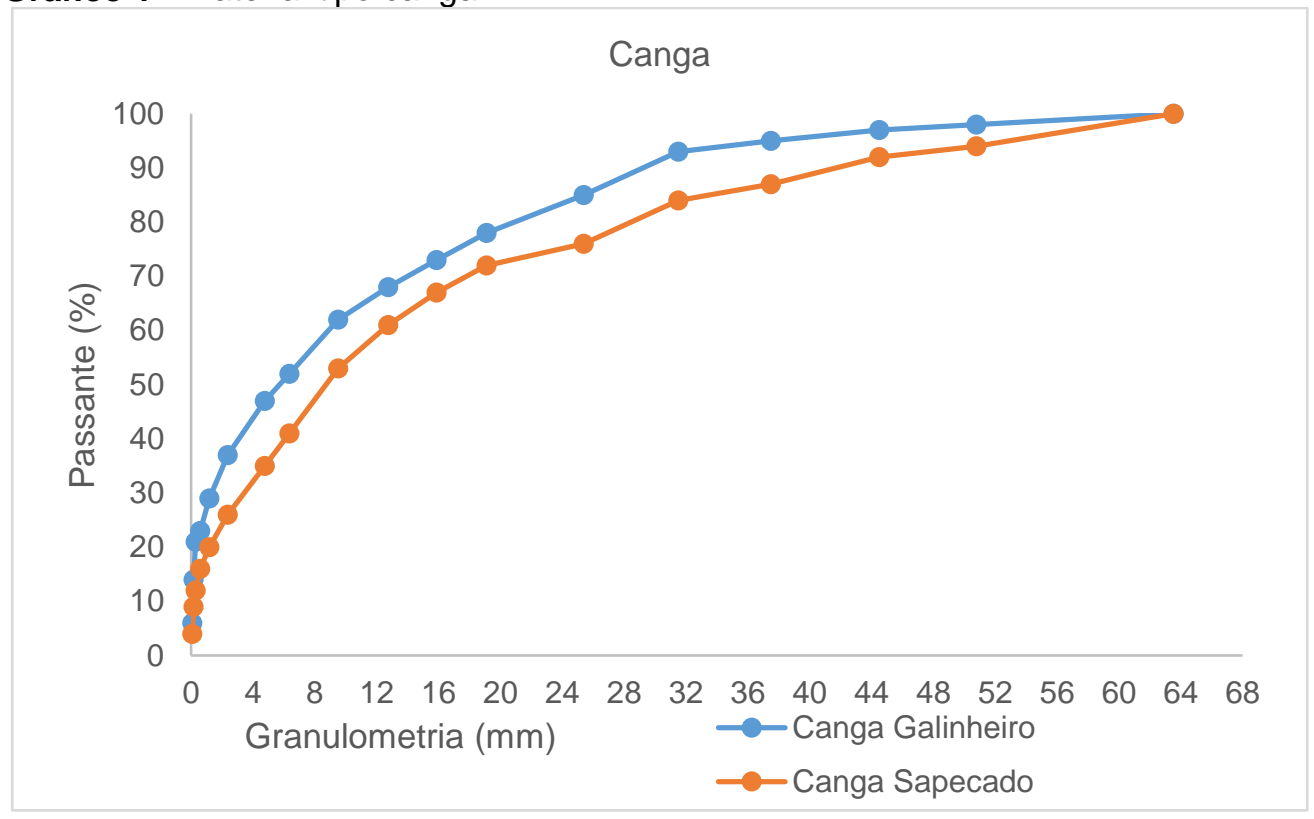

Já a Tabela 2, apresenta os resultados conforme a média das 5 amostras de material tipo hematita.

Tabela 2 - Classificação de granulometria hematita Hematita Galinheiro

Hematita Sapecado

\begin{tabular}{|c|c|c|c|}
\hline Tamanho (mm) & Passante (\%) & Tamanho (mm) & Passante (\%) \\
\hline 63,54 & 100 & 63,54 & 100 \\
\hline 50,8 & 98 & 50,8 & 90 \\
\hline 44,5 & 91 & 44,5 & 89 \\
\hline 37,5 & 83 & 37,5 & 86 \\
\hline 31,5 & 77 & 31,5 & 82 \\
\hline 25,4 & 68 & 25,4 & 79 \\
\hline 19,1 & 61 & 19,1 & 74 \\
\hline 15,87 & 60 & 15,87 & 71 \\
\hline 12,74 & 60 & 12,74 & 66 \\
\hline 9,52 & 54 & 9,52 & 60 \\
\hline 6,35 & 53 & 6,35 & 48 \\
\hline 4,76 & 38 & 4,76 & 41 \\
\hline 2,38 & 29 & 2,38 & 26 \\
\hline 1,19 & 24 & 1,19 & 16 \\
\hline 0,6 & 21 & 0,6 & 12 \\
\hline 0,3 & 18 & 0,3 & 9 \\
\hline 0,15 & 13 & 0,15 & 6 \\
\hline 0,07 & 9 & 0,07 & 3 \\
\hline
\end{tabular}

Revista Produção Online. Florianópolis, SC, v. 21, n. 2, p. 576-607, 2021 
O Gráfico 2 apresenta a dispersão dos dados da Tabela 2 conforme os valores amostrados.

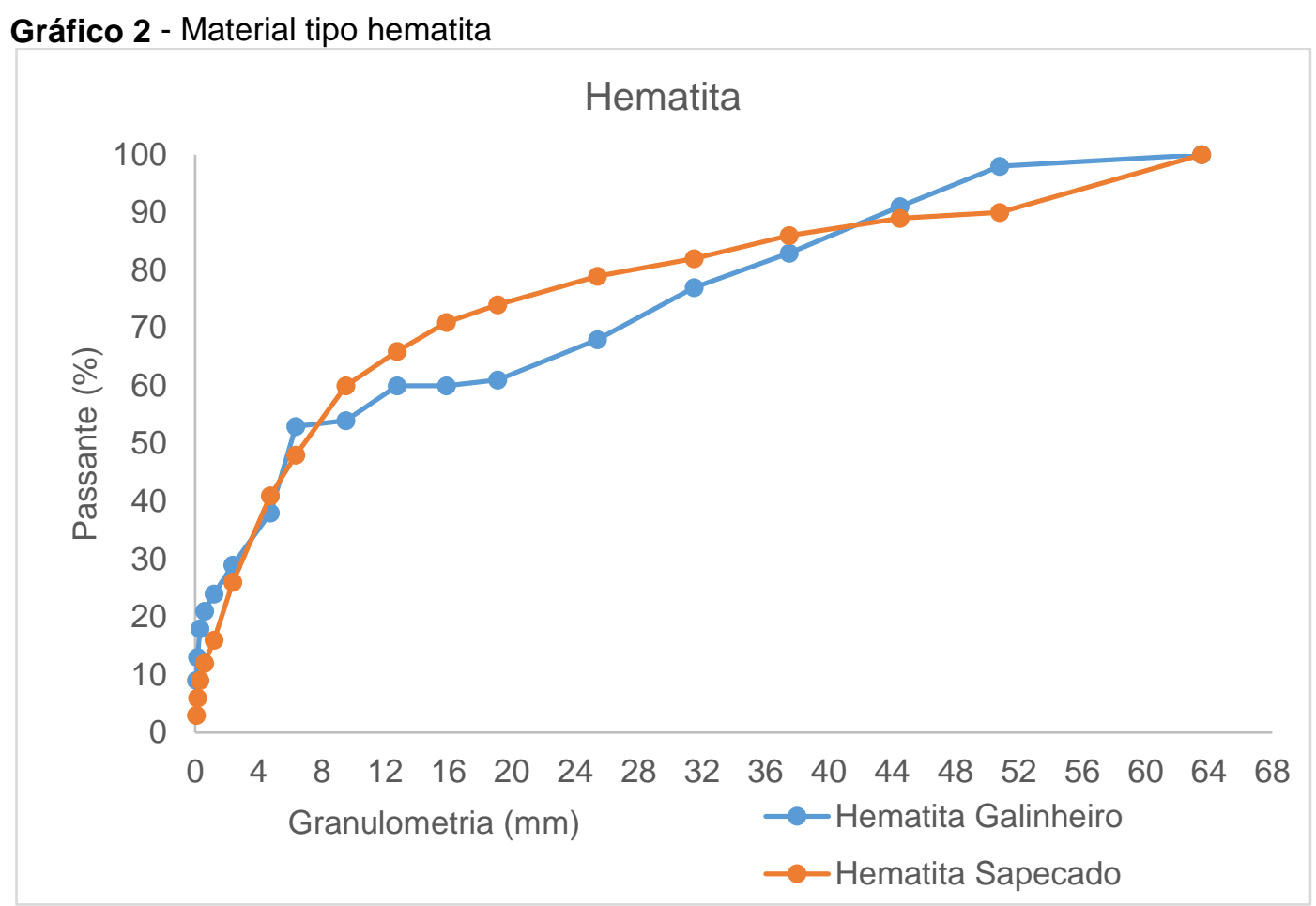

Portanto, os dados inseridos nos pontos de decisões (Figura 8), são os percentuais de material passante e retido (ver Tabela 1 e Tabela 2) na classificação granulométrica que ocorre nas PE01 e PE02. A Figura 9 mostra como a lógica foi implementada no modelo de simulação para o caso da PE01, ou seja, o percentual dos materiais com granulometria menor (passante) que $32 \mathrm{~mm}$ (ver Tabela $1 \mathrm{e}$ Tabela 2) seguem para o processo de alimentação, ao passo que o material com granulometria maior que $32 \mathrm{~mm}$ (retido) segue para o processo de britagem 2.

Para o ponto de decisão referente a classificação que ocorre na PE02 foi implementada lógica semelhante a observada na Figura 9. Lembrando que para este caso, a porcentagem de material retido é referente ao material com granulometria maior que 19 mm (ver Tabela 1 e Tabela 2) e o material passante é correspondente ao material com granulometria menor que $19 \mathrm{~mm}$. 
Figura 8 - Material passante e retido PE01

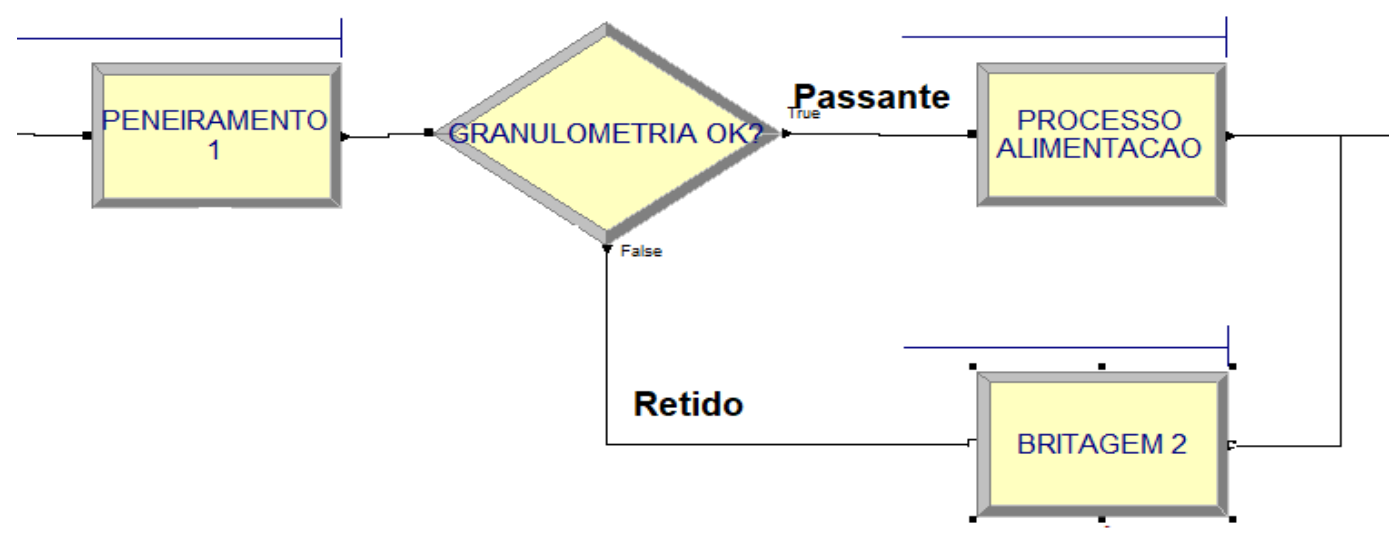

\subsection{Tradução do modelo}

Nesta etapa, segundo Law (2007), deve-se transcrever o processo real para uma linguagem computacional. Para tanto, foi desenvolvido um modelo computacional representando o sistema real, utilizando o software ARENA ${ }^{\circledR}$ como ferramenta de modelagem.

\subsection{Verificação e validação do modelo}

Segundo Law (2007) e Banks et al. (2010) esta etapa consiste em verificar se o sistema computacional representou de forma adequada o sistema operacional real, ou seja, deve-se garantir que a lógica implementada no modelo corresponda à lógica encontrada no sistema real. Para tanto, foi realizada uma primeira simulação com o intuito de verificar e validar a lógica do sistema computacional.

O modelo desenvolvido foi validado visto que a lógica implementada está representando de forma adequada e correta as operações e processos correspondentes ao sistema real.

\subsection{Desenvolvimento dos cenários}

Considerada etapa fundamental para um projeto de simulação, esta fase consiste na experimentação de diversas alternativas a fim de antecipar os efeitos 
produzidos no sistema por alterações ou pelo emprego de outros métodos em suas operações.

Neste trabalho foram propostos 5 cenários, sendo que 4 destes cenários tinham o objetivo de demonstrar o impacto na produção mediante a variação granulométrica do material que alimenta a usina. Tais cenários podem ser observados conforme Quadro 4.

Quadro 1 - Cenários considerados

\begin{tabular}{|c|c|c|c|c|}
\hline \multirow{2}{*}{ Cenários } & \multicolumn{2}{|c|}{ Peneira PE01 } & \multicolumn{2}{c|}{ Peneira PE02 } \\
\cline { 2 - 5 } & Passante \% & Retido \% & Passante \% & Retido \% \\
\hline Cenário 01 & 94 & 6 & 78 & 22 \\
\hline Cenário 02 & 86 & 14 & 72 & 28 \\
\hline Cenário 03 & 81 & 19 & 61 & 39 \\
\hline Cenário 04 & 84 & 16 & 74 & 26 \\
\hline
\end{tabular}

Vale destacar que: o cenário 01 consistiu na alimentação do processo pelo material canga advindo da frente de lavra Galinheiro; o cenário 2 consistiu na alimentação do processo pelo material canga proveniente da frente de lavra Sapecado; já o cenário 3 consistiu na alimentação do processo pelo material hematita advindo da frente de lavra Galinheiro e por fim, o cenário 4 consistiu na alimentação do processo pelo material hematita advindo da frente de lavra Sapecado.

Os quatro cenários propostos por esse trabalho, foram implementados no modelo computacional realizando alterações nos pontos de decisões (ver Figura 8) programados no modelo de simulação. Para tanto, a cada simulação correspondente a um novo cenário, foram alterados os percentuais de minério retidos e passantes nas peneiras PE01 e PE02 referentes a cada cenário, conforme Quadro 4.

O cenário 05 proposto, foi baseado na análise dos dados do relatório de simulação emitido pelo ARENA ${ }^{\circledR}$. Dessa forma, o cenário 05 consistiu em uma alteração do sistema produtivo, com a adição de uma correia transportadora e a inversão do sentido de rotação do AL02, conforme representado pela Figura 10. Ainda como alternativa proposta pelo cenário 05 , foi a substituição das telas da PE01 por telas de $19 \mathrm{~mm}$, com o intuito de classificar e retirar do material que 
alimentava a usina (ROM) o material que já se encontra na granulometria especificada do produto coarse sínter feed, diminuindo portanto, o volume de material nos processos seguintes.

Figura 9 - Alteração realizada no modelo (Cenário 05)

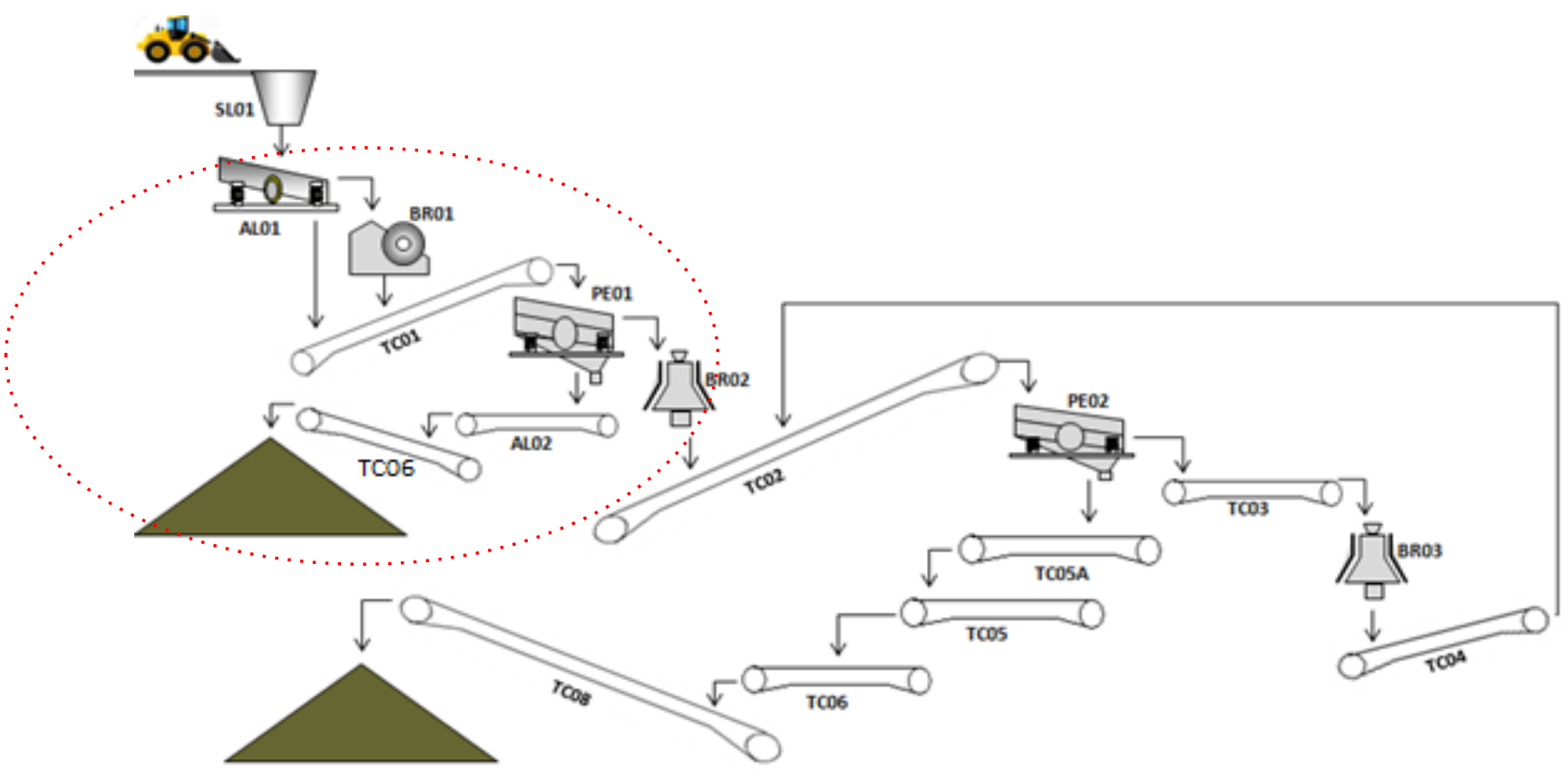

\subsection{Verificação dos dados de saída e documentação}

É importante realizar uma análise estatística dos resultados, e compará-los com os resultados das diversas iterações do sistema, e se necessário, deve submeter tal sistema a mais replicações, obtendo melhores resultados (FREITAS FILHO, 2008). Contudo, no caso deste trabalho, não foi realizada a confirmação estatística da aderência do modelo ao sistema real simulado, devido a restrições de hardware que impossibilitaram que as simulações dos cenários fossem realizadas com o número de replicações e tempo de simulação adequados.

Conforme Banks et al. (2010) a documentação tem a finalidade de demonstrar como a simulação foi realizada permitindo a outros indivíduos desenvolver programações similares. No caso do presente trabalho, a documentação consiste no desenvolvimento e apresentação da própria pesquisa, 
apresentando e detalhando todas as etapas necessárias referentes ao estudo de simulação proposto.

\section{ANÁLISE DOS RESULTADOS}

Mediante a simulação realizada, foi possível verificar o impacto gerado na produção da usina advindo dos diferentes tipos de materiais que alimentaram o processo. Dessa forma, observou-se que a granulometria do material impactou de forma significativa na capacidade de beneficiamento do sistema. Tal resultado está apresentado conforme Gráfico 3.

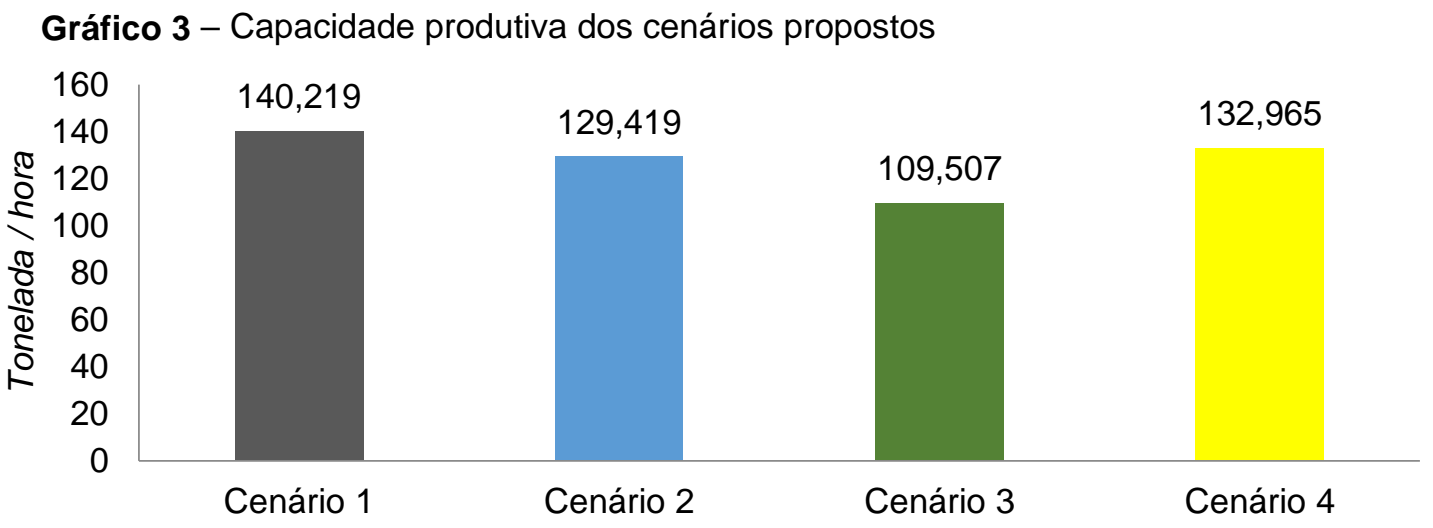

Conforme Gráfico 1, observa-se que o cenário 01 (material canga proveniente da mina Galinheiro) se apresenta como a alternativa com maior capacidade de produção em relação aos demais cenários.

Conforme uma análise realizada nos relatórios de simulação emitidos pelo software ARENA ${ }^{\circledR}$, foi possível identificar que a peneira PE02 é a restrição (gargalo) do processo, já que apresentou uma taxa de utilização elevada, apontando que tal equipamento está operando com $100 \%$ de sua capacidade em todos os cenários simulados. Tal análise pode ser observada conforme Tabela 3.

Tabela 3 - Taxa de ocupação dos recursos (cenários 01,02,03,04)

\begin{tabular}{lcccccc} 
& PE01 & PE02 & BR01 & BR02 & BR03 & AL01 \\
\hline Cenário 01 & $49 \%$ & $100 \%$ & $10 \%$ & $4 \%$ & $20 \%$ & $23 \%$ \\
Cenário 02 & $49 \%$ & $100 \%$ & $11 \%$ & $10 \%$ & $26 \%$ & $21 \%$ \\
Cenário 03 & $49 \%$ & $100 \%$ & $10 \%$ & $13 \%$ & $37 \%$ & $20 \%$ \\
Cenário 04 & $49 \%$ & $100 \%$ & $10 \%$ & $10 \%$ & $25 \%$ & $20 \%$ \\
\hline
\end{tabular}


Através da análise dos resultados provenientes das simulações dos cenários 01,02,03 e 04 bem como os dados apresentados na Tabela 3, foi proposto o cenário 05, visando reduzir o excesso de carga na PE02, e consequentemente, aumentar a capacidade produtiva do sistema modelado.

Inicialmente, realizou-se uma simulação do cenário 05 com a mesma alimentação utilizada nos cenários anteriores. Como resultado desta simulação, obteve-se uma produção de 146,47 toneladas/hora, resultando em um aumento de 6,5 toneladas/horas ou $4,26 \%$ de produção a mais que a produção encontrada nos cenários anteriormente simulados.

Contudo, após a verificação dos resultados de simulação, observou-se que os recursos operavam com uma taxa de ocupação reduzida, conforme apresentado na Tabela 4, permitindo então, realizar uma simulação com um valor maior de alimentação da usina, passando a ser de 4,5 toneladas/minutos.

Tabela 4 - Taxa de ocupação dos recursos (cenário 05)

\begin{tabular}{ccccccc} 
& PE01 & PE02 & BR01 & BR02 & BR 03 & AL01 \\
\hline Cenário 05 & $49 \%$ & $29 \%$ & $10 \%$ & $17 \%$ & $7 \%$ & $18 \%$
\end{tabular}

Dessa forma, a alimentação da usina foi alterada para uma taxa constante de 4.5 toneladas/minuto. Então, foi realizada uma nova simulação que retornou como resultado, uma capacidade produtiva de 239,99 toneladas/hora, correspondendo a um aumento de produção de 58,42\%. A comparação da produção horária de toneladas de minério obtida por meio do cenário 01 e cenário 05 está apresentada conforme Gráfico 4. 


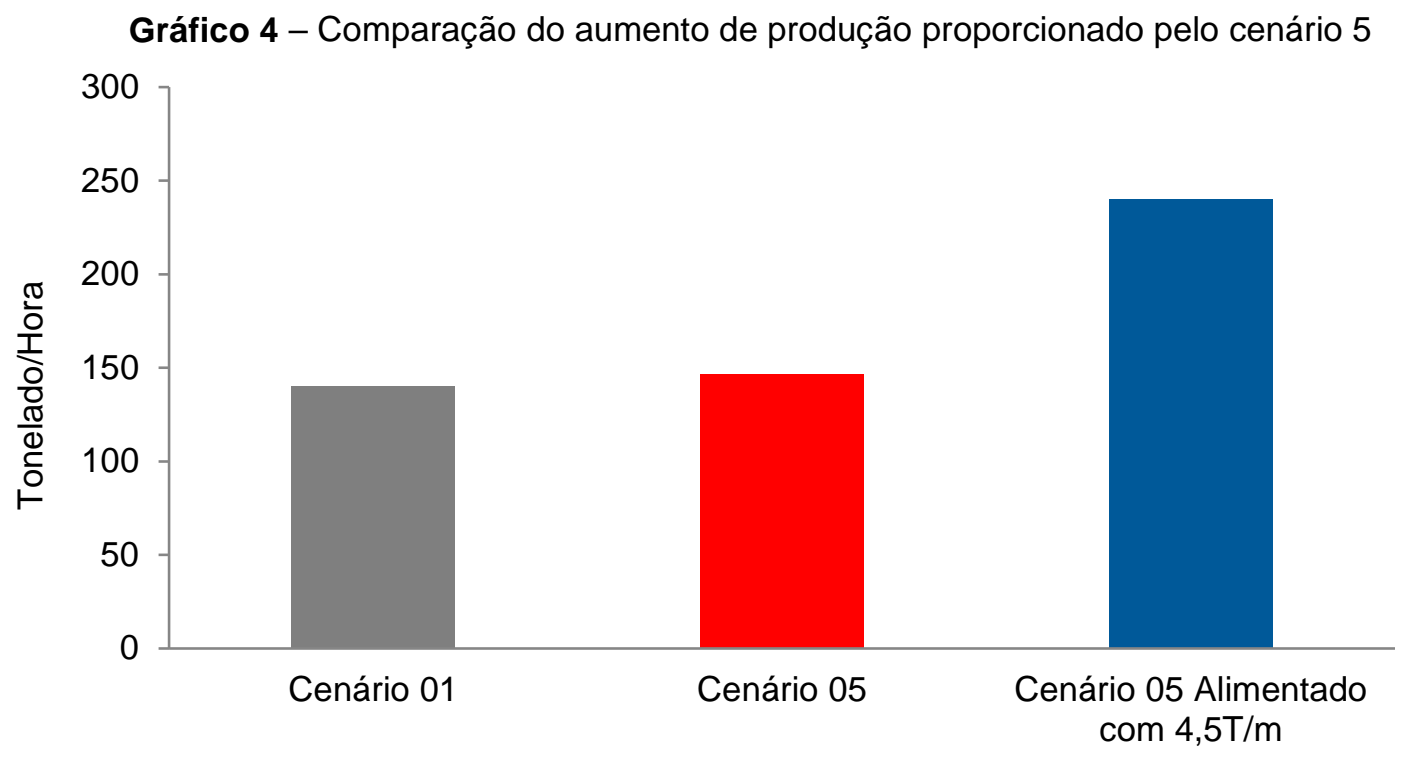

Além disso, a Tabela 5 apresenta a taxa de ocupação dos recursos referentes ao cenário 05 , podendo então concluir que tais recursos estão operando com uma taxa de utilização mais adequada.

Tabela 5 - Taxa de ocupação cenário 05 após adequação da taxa de alimentação

\begin{tabular}{ccccccc} 
& PE01 & PE02 & BR01 & BR 02 & BR 03 & AL01 \\
\hline $\begin{array}{c}\text { Cenário 05 (alteração } \\
\text { alimentação) }\end{array}$ & $80 \%$ & $47 \%$ & $17 \%$ & $28 \%$ & $11 \%$ & $29 \%$ \\
\hline
\end{tabular}

\section{CONCLUSÃO}

Este trabalho realizou um estudo de simulação de uma usina de tratamento de minério de ferro, visando analisar as interações do sistema e obter melhor ocupação dos recursos. Dessa forma, observou-se que mediante os cinco cenários simulados, o que proporcionou maior produção foi cenário 01, que se caracterizou por ser um cenário cuja alimentação foi realizada pelo material tipo canga, extraído da mina Galinheiro, sendo capaz de processar 7,25 toneladas/horas a mais que os demais cenários.

Após realizar a análise dos relatórios provenientes da simulação, observouse que a taxa de ocupação do recurso peneira PE02 era 100\%, apontando uma oportunidade de melhoria. Assim, foi proposto o quinto cenário, caracterizado pela implementação de uma nova correia transportadora que remove o material que já se encontra com a granulometria adequada do produto. 
Através deste novo cenário, obteve-se um aumento de produção de 6,5 toneladas/horas atingindo uma produtividade $4,26 \%$ superior aos cenários inicialmente desenvolvidos. Porém, ao analisar novamente os resultados da simulação, identificou-se uma nova oportunidade de melhorar a capacidade de produção do sistema, já que foi observado novamente uma taxa de ocupação reduzida dos recursos. Assim, foi proposto o aumento da taxa de alimentação do sistema, que nos 4 cenários anteriormente simulados era conforme uma distribuição normal com a seguinte característica: NORM $(2.95,0.408)$ minutos, passando então para uma nova alimentação de 4,5 toneladas/minutos.

Portanto, o modelo de simulação computacional representou de forma adequada o funcionamento real da usina, atingindo uma produção de 239,99 toneladas/hora conforme encontrado no cenário 05 , representando um aumento de $58,42 \%$ em relação aos cenários anteriores. Tal resultado, comprova, portanto, que a adequação do sistema é uma proposta relevante quando se trata do aumento da produtividade.

\section{REFERÊNCIAS}

ALEXANDRE, O, P; BECK, $\mathrm{N}$ e GIORGIO, T. Indicadores chave de desempenho e a gestão integrada da mineração. Rev. Esc. Minas. Ouro Preto, v. 65, 2012. https://doi.org/10.1590/S0370-44672012000400015

ANDRADE, E, L. Introdução à pesquisa operacional: métodos e modelos para a análise de decisões. 3. ed. Rio de Janeiro: LTC, 2002.

ARAÚJO, S, R; RODRIGUES, L, F; MENDES, J, C; PEIXOTO, R, A, F. Reverse logistics system applied to the reuse of iron ore tailings. Waste Management \& Research, v. 38, 2020. https://doi.org/10.1177/0734242X20944478

BANKS, J.; CARSON, J.; NELSON, B. Discrete-event system simulation. 4th.ed. New Jersey: Prentice Hall, 2005.

BANKS, J.; CARSON, J.; NELSON, B. Discrete-event system simulation. 5th ed. New Jersey: Prentice Hall, 2010.

BODON, P.; FRICKE, C.; SANDEMAN, T.; e STANFORD, C. Modeling the mining supply chain from mine to port: A combined optimization and simulation approach. Journal of Mining Science, v. 47, 2011. https://doi.org/10.1134/S1062739147020079

CARNEIRO, W. M. Modelo de simulação computacional para avaliação de segurança do tráfego de caminhões em minas a céu aberto. In: SIMPÓSIO DE PESQUISA 
OPERACIONAL E LOGÍSTICA DA MARINHA - SPOLM, 17., 2014. [Anais....], n.1, v.1. São Paulo, 2014. https://doi.org/10.5151/marine-spolm2014-126504

CECILIANO, W, R, A. Aplicação de um método de simulação: otimização na cadeia produtiva de minérios de ferro. São Paulo, 2007. Dissertação (Mestrado) Universidade de São Paulo.

CHAVES, A, P. Teoria e prática do tratamento de minérios. 2. ed. São Paulo: Signus Editora, 2002.

CHAVES, A, P.; PERES, A. E. C., Teoria e prática do tratamento de minérios/ britagem, peneiramento e moagem. v.3. 2. ed. São Paulo: Signus Editora, 2003.

CORRÊA, J. É.; MELLO, C. H. P.; PEREIRA, T. F. Uso de simulação de eventos discretos para avaliação de uma linha de montagem de uma empresa do ramo automotivo e os impactos do fator humano. Elocução: Revista Científica da Faex. n. 6 , 2014.

ÉNRIQUEZ, M. A. R. S.; FERNANDES, F. R. C.; ALAMINO, R. C. J. A. Mineração das grandes minas e as dimensões da sustentabilidade: recursos minerais \& sustentabilidade territorial, CETEM/MCTI, 2011.

FREITAS FILHO, P. J. Introdução à modelagem e simulação de sistemas: com aplicações em Arena. 2. ed. Florianópolis: Visual Books, 2008.

GAVIRA, M, O. Simulação computacional como ferramenta de aquisição de conhecimento. Dissertação (Mestrado em Engenharia de Produção) - Escola de Engenharia de São Carlos, Universidade de São Paulo, São Carlos, 2003.

GIL, A.C. Como elaborar projetos de pesquisa. São Paulo: Atlas, 2002.

GONÇALVES, P, G. Desenvolvimento de modelos de simulação para as atividades de decapeamento e lavra de uma mina de bauxita com o software Arena. Ouro Preto. Dissertação (Graduação), Departamento de Engenharia de Minas da Universidade Federal de Ouro Preto, 2019.

INSTITUTO BRASILEIRO DE MINERAÇÃO. Informações e análises da economia mineral brasileira (2018). Disponível em: http://www.ibram.org.br/. Acesso em: 15 set. 2019.

KELTON, W, D.; RANDAL, S, P.; STURROCK, D, T. Simulation with arena. 3. ed. McGraw-Hill, 2004.

LAW, A, M. Simulation Modeling and Analysis. Arizona, Estados Unidos: Mc Graw Hill, 2007.

LAW, A. M. e KELTON, W. D. Simulation modeling and analysis. Singapore: McGrawHill, 1991.

LUZ, A, B; SAMPAIO, A, S; FRANÇA, S, C, A. Tratamento de Minérios.5. ed. Rio de Janeiro: CETEM/MCT, 2010. 
MARIA, M. A.; FERNANDES, F. R. C.; ALAMINO, R.C.J. Recursos minerais e comunidade: impactos humanos, socioambientais e econômicos. Rio de Janeiro, CETEM/MCTI, 2014.

MINISTÉRIO DE MINAS E ENERGIA. Plano nacional de mineração 2030 (PNM 2030) Brasília: MME, 2019.

NEGAHBAN, A; SMITH, J, S. Simulation for manufacturing system design and operation: Literature review and analysis. Journal Manuf. Syst, v. 33, 2014.

https://doi.org/10.1016/j.jmsy.2013.12.007

NASCIMENTO, R, N; RANGEL, A, J, J; RANGEL, L, C. Uma abordagem para construção de modelos de simulação a eventos discretos para aplicação como um recurso didático. Produto \& Produção, v. 16, n. 2, 2014. ttps://doi.org/10.22456/1983-8026.48192

PANAGIOTOU, G. N., Discrete mine system simulation in Europe. International Journal of Surface Mining, Reclamation and Environment, v. 13, 1999.

https://doi.org/10.1080/09208119908944208

PEDGEN, C. D., SHANNON, R. E. e SADOWSKI, R. P. Introduction to simulation using SIMAN. New York: McGraw-Hill, 1999.

PIDD, M. Modelagem empresarial: ferramentas para tomada de decisão. Porto Alegre: Bookman, 1998.

RACIA. I, M. Desenvolvimento de um modelo de dimensionamento de equipamento de escavação e de transporte em mineração. Porto Alegre. Dissertação (Mestrado) Programa de Pós-Graduação em Engenharia de Minas, Metalúrgica e de Materiais Universidade Federal do Rio Grande do Sul, 2016.

RODRIGUES, F, L. Análise comparativa de metodologias utilizada no despacho de caminhões em minas de céu aberto. Belo Horizonte. Dissertação (Mestrado), Departamento de Engenharia de Produção na Universidade Federal de Minas Gerais, 2006.

RODRIGUES, L, H. Developing an approach to help companies synchronise manufacturing. Thesis (Doctorate), Department of Management Sciences. University of Lancastes, 1994.

SANTOS, J. A.A. et al. Modelagem, simulação e otimização da dinâmica operacional de um pequeno restaurante: um estudo de caso. Universidade Tecnológica Federal do Paraná. Campus de Medianeira, 2014. https://doi.org/10.18674/exacta.v6i1.971

SCHNEIDER C. et al. Beneficiamento de minérios. Centro de Tecnologia Mineral CETEM - Recursos Minerais no Brasil: problemas e desafios - Rio de Janeiro: Academia Brasileira de Ciências, 2016.

SILVEIRA, D.T.; GERHARDT, D.T. Métodos de pesquisa. Porto Alegre: Editora da UFRGS, 2009.

SOUZA, T, F. A Simulação a eventos discretos como ferramenta de apoio à tomada de decisão em empresas do ramo de mineração: aplicação em uma unidade da 
yamana gold. Ouro Preto. Dissertação (Mestrado), Departamento de Engenharia de Minas Universidade Federal de Ouro Preto, 2009.

SZYMANKIEWICZ, J, MCDONALD, J, TURNER, K. Solving business problems by simulation. London: McGraw-Hill Book Company, 1988.

TURBAN, E.; MCLEAN, E.; WETHERBE, J. Tecnologia da informação para gestão. 3 Edição. Porto Alegre: Bookman, 2004.

VAGENAS, N. Applications of discrete-event simulation in Canadian mining operations in the nineties. International Journal of Surface Mining, Reclamation and Environment, v. 13, 1999. https://doi.org/10.1080/09208119908944213

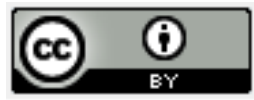

Artigo recebido em: 03/04/2021 e aceito para publicação em: 02/07/2021

DOI: http://dx.doi.org/10.14488/1676-1901.v21i2.4287 